\title{
President's Report 2016
}

The IMS committee had one change for 2016, with D. Malone (MU) being elected as secretary following R. Quinlan's greatly valued term in that office.

The year marks the 40th anniversary of the society and there are two 1976 meetings that we celebrate which might loosely be described as conception and birth. On April 19th, 1976, in room WR20 at Trinity College, a gathering of mathematicians proposed the formation of the Irish Mathematical Society, and began the work required to ensure this idea came to fruition. On December 20th of that year, the first meeting proper of the society took place where the constitution was adopted, the membership list recorded and officers and committee were elected.

In recognition, our annual "September" meeting was held in April and, like the spawning salmon, returned to Trinity College for the event. We thank Trinity, and in particular local organisers R. Timoney and V. Dotsenko, for the invitation and a most enjoyable meeting. While we took advantage of the gathering to have an ordinary business meeting of the society, the Annual General Meeting must occur post-July and so was held on the second of the anniversaries, December 20th, at UCD, at which this report was presented.

In April, I attended the European Mathematical Society presidents' meeting which was held this year in Budapest during the first weekend of April. It is a useful forum, in the first instance, to hear and comment on reports from the president of the EMS and, in the second, to have the opportunity to discuss with counterparts in the many national societies. The theme for open discussion on the Sunday was mathematical education where attendants had an opportunity to discuss and compare experiences of mathematical teaching at second and third level. A report of the meeting is available.

Moving beyond Europe, the national adhering body to the International Mathematical Union (IMU) is the Royal Irish Academy where mathematical affairs are dealt with by the Physical, Chemical and Mathematical Sciences committee. While there is often overlap between the Academy and IMS committee membership, this was 
not a formal state of affairs. It is sensible that the two committees do not work in isolation and entirely appropriate that the society membership should have a line of repesentation to the PCMS committee. Following a letter from the society inviting closer working relations, it was agreed that the IMS president, or nominee thereof, will in future be an invited member of the PCMS committee.

The society funded five meetings in 2016:

(1) Numeracy: A Critical Skill in Adult Education. The 23rd Annual International Conference of the ALM., Jul 3-6, Maynooth University.

(2) Young Functional Analysts Workshop, Apr 6-8, Queens University Belfast.

(3) Groups in Galway 2016, May 20-21, NUIG.

(4) Irish Geometry Conference 2016, May 6-7, TCD.

(5) 10th Annual Irish Workshop on Mathematics Learning and Support Centres, May 29, NUIG.

I thank our treasurer, Goetz Pfeiffer, for most efficient handling of the application process. We receive more applications than we can provide funding for and choosing which meetings to benefit is a difficult and onerous task for the committee.

I can report that the IMS now engages in an activity known as "tweeting" under the pseudonym @irishmathsoc. The good stuff is still to be found in the Bulletin, as I trust it will be for the next forty years.

M. Mackey

December, 2016

E-mail address: mackey@maths.ucd.ie 